\title{
Proceeding
}

Supplementary Issue: Spring Conferences of Sports Science. Costa Blanca Sports Science Events, 14-15 June 2019. Alicante, Spain.

\section{Overtraining syndrome, stress and nutrition in football amateur athletes}

\author{
PIETRO MONTESANO ${ }^{1}$, MAURIZIO DI SILVESTRO ${ }^{2}$, GIULIA CIPRIANI ${ }^{3}$, FILOMENA MAZZEO ${ }^{4}$ \\ ${ }^{1}$ Department of Motor Sciences and Wellness, University of Naples Parthenope, Naples, Italy \\ ${ }^{2}$ Fitness Area 51, Italy \\ ${ }^{3}$ Gavazzeni Foundation, Bergamo, Italy \\ ${ }^{4}$ Department of Sport Sciences and Wellness, University of Naples Parthenope, Naples, Italy
}

\begin{abstract}
In competitive sports is important optimizing and improving the recovery-stress state. We aimed to investigate the overtraining syndrome in the football, modulating the agonistic training and evaluating the nutritional status of the young amateur soccer players, thought monitoring of the capacity of endurance and strength in a sample of twenty athletes between the ages of 18 and 33 (mean $22+/-4.43$ SD). Overtraining syndrome is a condition of physical, behavioural and emotional stress in sports and occurs when the physical activity is so intense as to prevent the athlete from performing a correct recovery totally eliminating the sense of fatigue. The athletes, from September 2016 to April 2017 were monitored with anthropometric tests (BMI calculation), nutritional tests (Recall test) and sportive (Cooper and Sargent test) to prevention of the overtraining syndrome with initial, intermediate and final measurements. Each player, during the observational period, performed normal athletic training sessions and participating two additional monthly sessions, for a total of sixteen sessions, with free overloads and, after intermediate verification, the exercises has been modified to reduce overtraining phenomenon. Tests initial results have been positive for defenders and midfielders while at the end of the search goalkeepers and forwards have significantly improved the performances. The total percentage increase of sample is around $+/-4 \%$ and the study confirmed that by modulating the intensity of training and controlling the athletes' diet, it is possible to reduce or eliminate overtraining effects. Keywords: Overtraining; Nutrition; Endurance; Strength; Football; Health.
\end{abstract}

\section{Cite this article as:}

Montesano, P., Di Silvestro, M., Cipriani, G., \& Mazzeo, F. (2019). Overtraining syndrome, stress and nutrition in football amateur athletes. Journal of Human Sport and Exercise, 14(4proc), S957-S969. doi:https://doi.org/10.14198/ihse.2019.14.Proc4.58

Corresponding author. Department of Motor Sciences and Wellness, University of Naples Parthenope, Naples, Italy.

E-mail: pieromontesano@libero.it

Supplementary Issue: Spring Conferences of Sports Science. Costa Blanca Sports Science Events, 14-15 June 2019. Alicante, Spain.

JOURNAL OF HUMAN SPORT \& EXERCISE ISSN 1988-5202

(c) Faculty of Education. University of Alicante

doi:10.14198/jhse.2019.14.Proc4.58 


\section{INTRODUCTION}

The athletic physical form, regardless of the discipline practiced, is the result of constancy in training, in free form and with and without tools, which determine the improvement of performance in relation to skill strength, endurance and speed (Kellmann, 2010; Montesano\& Mazzeo, 2018;). The metabolic and bioenergetic mechanisms are present in all training processes (Altavilla et al, 2018; Perrotta et al., 2017) but the differences are evident in individual and team sports. Individual sports subject the athlete to constant stresses while those of the team allow an alternation between work and recovery (Kellmann, 2010).

Football, team discipline, requires athletes to engage in bioenergetic alternating, anaerobic-aerobic (Cipryan, Gajda, 2011) and multiple factors can affect the player's sporting performance. Exogenous factors such as climate and condition of the field, and endogenous, psychophysical factors such as workload, overtraining, stress condition (Nédélec et al.), lifestyle. All this factors are important for health of the athlete and is indispensable the attention to a correct and balanced diet, including all classes of nutrients (Sirico et al., 2018), in particular fruits and vegetables (American College of Sports Medicine, 2000; ), to prevent inflammatory processes (Suzuki K. et al, 2002), risks of accidents and have a correct postural setting (Montesano, Mazzeo, 2018). The nutritional status (Mazzeo et al. 2016) plays a fundamental role in optimizing the performance of athletes; this not only (American College of Sports Medicine, 2000), balancing appropriately all the micro and macro-nutrients that the human body needs and selecting the food and beverages but monitoring the times when they must be taken before, during and after training and the official races.

The nutrition of the sportsman must ensure the contribution of energy, in the form of calories and promoteand maintain a high level of psychophysical wellbeing (Mazzeo, 2016; Chulvi-Medrano et al., 2019). There are variations in energy expenditure depending on the type of sports activity considered and practiced (Hawley et al, 1995) but also in relation to the registry and morphological variables (Illiano et al 2017; Montesano et al., 2013); it is important to draw up a training protocol with a proper nutritional structure associated, where necessary, with a correct integration of vitamins and / or essential fatty acids (Ashbaugh., McGrew., 2016; Mazzeo et al., 2016).

In football, sport with a high level of dexterity and cognitive application in which explosiveness, speed and ability (Montesano, 2014) to reiterate intense efforts with no decrease in power are important (Bangsbo, 2015), it has been demonstrated that players, particularly those of elite, end the race - with a depletion of glycogen reserves (Nielsen et al, 2010). Some experiments have shown that the prepared glucose load can guarantee an improvement in sports performance (Nielsen et al, 2010; Mazzeo, 2016b).

The situation is different for amateur athletes whose monitoring has been oriented towards the phenomenon of dehydration, which can also result in a loss of more than $1.5 \%$ of the initial body weight. Body composition and physical condition of the athlete may vary depending on workload and psychophysical stress (Burke, Hawley, 1997; Mazzeo, 2016) that may come into play, not only on the basis of the food component (Bangsbo, 2015; Nedelec et al., 2015). An excess of training load or reduced hydration or unbalanced diet can negatively affect body composition, thus initiating inflammatory processes and, consequently, increasing the risk of injury (Li et al, 2015; Suzuki et al, 2002). During periods of sporting activity, energy reserves must be replenished through adequate "primary" nutritional, among gender diversity (Mazzeo, Santamaria, Montesano, 2019), inputs - energy, carbohydrates and water - and "secondary" - proteins, minerals, vitamins and fibre. 
The aforementioned contributions vary depending on the effort required by the body according to the sports season, and the sport practiced, with a diversification of the pre, during and post-race periods and avoiding interference meals, easily digestible, with training and / or official competition (Burns, Schiller, Merrick et al., 2004). It is important to take food 3-4 hours before the competition, to prevent and monitor dehydration by ingesting, 30-40 minutes before the competition, a supplement in the form of a drink and, in the post-race phase, is necessary to reintegrate the water reserves, assuming a quantity of liquids equal to the kg lost plus another $50 \%$, as well as glycogen, taking $1 \mathrm{gr}$ of glucose per body weight, accumulated in pre-race (Galanti, Stefani, Scacciati et al., 2015; Altavilla et al., 2018). The reintegration of energy and water reserves must be controlled in order to avoid the absorption of high doses of supplements, or associations of supplements or a consumption of them for a long period, which can cause damage to the liver, kidney and heart (Rescigno et al, 2018). These conditions together with an imbalance between training and recovery loads cause a dysfunction of the neuroendocrine system at the hypothalamic level determining the overtraining conditions.

\section{Overtraining syndrome}

Overtraining, or over-training (Montesano, 2018) syndrome, is a condition of physical, behavioural and emotional stress in sports and occurs when the physical activity practiced is so intense as to prevent the athlete from performing a correct recovery totally eliminating the sense of fatigue. The response that the body puts into action when it is subject to the prolonged effects of various types of stress such as physical, mental, social or environmental stimuli (Tachè, 2014).

Generally the phenomenon affects athletes of high-medium level, but it can also occur in simple non-agonistic athletes who undergo high workloads (Fry, Kraemer, 1997) or in any case excessive compared to the individual capacity of endurance and the state of form. It can affect both athletes who practice individual sports and those who practice team sports.

The symptoms that can make the overtraining emerge, as there are no diagnostic tests, are due to the lasting reduction of the performance, the feeling of fatigue, excessive muscle pain, depression and mood change, the increase in resting heart rate and of arterial pressure, insomnia, persistent flu symptoms, amenorrhea or oligomenorrhea in women and ultimately reduced appetite and weight loss. At the blood level there are variations in glutamine, neuromuscular excitability (NME), iron and ferritin, haemoglobin and haematocrit and urinary catecholamines (Mackinnon, 200). Testosterone and cortisol and the parameters of the immune system are also altered in general (Mazzeo, 2018). Therefore, there are many factors that contribute to the realization of an overtraining syndrome and the organism's reaction (Selye, 1956) can be identified in three phases:

- Alarm phase, biochemical and hormonal reactions: in this phase the body responds to stressors by implementing psychophysical mechanisms of adaptation to stress, for example increased heart rate, blood pressure, muscle tone and psychophysiological activation;

- Phase of resistance, the body adapts in a stable way: during this phase the body tries to fight and counteract the negative effects of prolonged fatigue, producing specific hormonal responses from the endocrine component e.g. adrenal gland;

- Stage of exhaustion collapse of the defences and inability to adapt further: in this phase the stressors continue to act, generating a state of oppression of the subject with consequent negative effects on the somatic and psychic structure. In some cases, the phenomenon of overreaching can occur, a transitory reduction in the capacity to perform, the duration of which is relatively short (Mohr et al., 2005). 


\section{MATERIALS AND METHODS}

The monitoring was carried out through the evaluation of the nutritional status, with a detailed analysis of the anthropometric characteristics (weight, height, plicometry and impedancemetry), and an assessment of the hydration status of the team athletes observed with particular attention to any differences (especially terms of FFM, FM and ECW) based on the technical-tactical role and the training program performed.

\section{Participants}

The research was developed in the 2016-2017 sport year on a sample of twenty-six male athletes, aged between 18 and 33 years and with an average age of $22+/-4,439$ SD, registered for a participating team at the football amateur championship.

Each player, during the observation period from September 2016 to April 2017, performed the normal athletic training sessions following the indications of the staff they belonged to and have participated in two additional monthly sessions, for a total of sixteen sessions, with overloads and elastic resistances.

\section{Objectives}

The main objective of research has been preventing overtraining syndrome during the Championship verifying endurance and explosive strength tests results with administration of combined training sessions, with controlled diet, characterised by the use of free overloads with elastic resistances in place of traditional training with weights only.

\section{Tests}

Anthropometric and nutritional tests

The measurements of height and body weight, parameters necessary to calculate the Body Mass Index (IMC or BMI) with the equation BMl = body weight $[\mathrm{kg}] /$ height [m2], were carried out with the help of an anthropometer (height) and with a scale (body weight). The measurement of body weight was carried out under standard conditions: with the subject on a fast, without shoes and clothes, with only underwear. A measurement scale has been used.

The assessment of nutritional status was carried out with the help of a food diary, consisting of cards, in pocket format, and structured in such a way as to facilitate the compilation and avoid forgetfulness, suitable to provide a qualitative and quantitative estimate, in household measures and portions (glasses, cups, spoons, cans, individual packs) of the diet followed by the athletes during 3 typical days during the course of the year.

The analysis of the data obtained was carried out with the help of the NutriSurvey database. This program was obtained from an English translation of a German software used in the nutritional field, the EBISpro. Inside there is a wide range of functions including nutrient analysis, calculation of energy needs, the ability to design a diet, dietary history, the frequency of food consumption and the possible search for particular recipes specific for the various nationalities. The program allows the use of national and international nutritional tables.

Sargent test

Detection of explosive strength through the Sargent test (with use of a rope graduated in $\mathrm{cm}$ on the wall): 
a) Detection in height, of metric graduation when starting: athlete positioned next to a wall, where there is a metric string in $\mathrm{cm}$, with tense lower limbs and one arm outstretched. Mark the height reached by the fingers ( $h 1$ );

b) Athlete in squat position $\left(90^{\circ}\right)$ performs a jump and measurement the highest point touched by the fingertips on the metric rope (h2);

c) The value of the elevation explosive strength is defined as the metric difference between the height reached jumping (b) and the initial (a) that is h2 - h1.

\section{Cooper test}

The distance covered by the athlete in twelve (or less) minutes of run is measured, referring to the age and sex of the subject, to assess their endurance.

\section{Content Training}

Isotonic and isometric strengthening exercises during training sessions in the gym with medicinal balls of varying weight between $1 \mathrm{~kg}$ and $3 \mathrm{~kg}$; lateral slipping off the line right and left; repeated shots on goal to varying distances and angles; changes in direction; sprint with speed balls changes; gaits: skip high, medium, sprint jump; small obstacles; rope; leaps and multiple leaps; half-squat-jump with weight belt.

The analytical methodology (Montesano, 2014) has favoured the development of the individual fundamentals, passage and shot, for each exercise with the use of the regulatory flask and of the medicinal balls. During the strengthening sessions (Galazoulas, 2017) for the exercises for the steps the athletes used the medicinal balls with a weight ranging from 1 to $3 \mathrm{~kg}$. while for the enhancement of the shooting technique they used only a medicinal ball weighing $1 \mathrm{~kg}$ alternating with the regulatory tender.

\section{Materials and resources}

- football field with the use of a single goal post

- regular footballs

- cones

- weight belt

- 2 instructors

- 10 strikers

- 1 rope graduated in $\mathrm{cm}$ for height metric measurements

- 2 operators detectors of distances in height

- medicinal flasks weighing between 1 and $3 \mathrm{~kg}$.

- weight scale

- Detection grids

\section{RESULTS}

\section{Anthropometric Parameters}

Each parameter (Table 1) was analysed in all athletes (through an average of the values +/- SD) in order to highlight differences in the anthropometric parameters related to the role occupied in the field (and consequently to the type of work performed). 
The average height of the athletes is about $180 \mathrm{~cm}$, but the analysis of the data collected and differentiated according to the role shows that the athletes who play the role of goalkeeper (Montesano 2016) are the highest compared to the guys who play the role of attacker, whose height is lower.

The average body weight of the athletes is about $76 \mathrm{~kg}$ but from the analysis of the data collected and differentiated according to the role it appears that the goalkeepers have the highest weight while the attackers have the lowest weight. The abdominal fold presents higher values in the athletes who occupy the role of defender; that performed on the front thigh is higher in the athletes who occupy the role of goalkeeper in the field as well as the measurement of the pectoral plica. The summation of the 3 folds appears to be higher in the athletes who occupy the role of goalkeeper in the field.

Table 1. Anthropometric parameters of the athletes who participated in the study

\begin{tabular}{lllllcccc}
\hline $\begin{array}{l}\text { Height } \\
\text { range } \\
(\mathrm{M})\end{array}$ & $\begin{array}{l}\text { Average } \\
\text { height } \\
(\mathrm{Cm})\end{array}$ & $\begin{array}{l}\text { Weight } \\
\text { range } \\
(\mathrm{kg})\end{array}$ & $\begin{array}{l}\text { Average } \\
\text { weight } \\
(\mathrm{Kg})\end{array}$ & $\begin{array}{l}\text { Range plica } \\
\text { abdominal }\end{array}$ & $\begin{array}{l}\text { Range } \\
\text { plica } \\
\text { Thigh } \\
\text { front }\end{array}$ & $\begin{array}{l}\text { Range } \\
\text { plica } \\
\text { pectoral }\end{array}$ & $\begin{array}{l}\text { Range } \\
\Sigma \text { folds }\end{array}$ \\
\hline Total & $160-190$ & $180+/-6$ & $\begin{array}{l}61,4- \\
94,9\end{array}$ & $76+/-7$ & $6-18$ & $6-16$ & $4-10$ & $16-43$ \\
\hline
\end{tabular}

The percentage of lean mass (FFM) is greater in midfielders, compared to athletes who occupy different roles in the field.

The percentage of fat mass (FM) is higher in attackers, compared to athletes who occupy different roles in the field.

The percentage of Extracellular Water (ECW) is higher in goalkeepers, compared to athletes who occupy different roles in the field.

The percentage of muscle mass (MM) is higher in midfielders, compared to athletes who occupy different roles in the field.

The percentage of Total Body Water (TBW) is greater in midfielders and goalkeepers than athletes who occupy different roles in the field.

Basal Metabolism (BMR) is greater in midfielders than athletes who occupy different roles in the field.

The ratio Sodium / Potassium ( $\mathrm{Na} / \mathrm{K}$ ), a retention index, is higher in goalkeepers than in athletes who occupy different roles in the field.

\section{Food Diary and Recall 24H}

Most athletes eat at the team cafeteria. Usually a simple menu is provided, based on pasta (with little seasoning) and meat. The consumption of fish and eggs is rare. A portion of vegetables is always present in the dish, but is not taken by everyone (some refuse its consumption for taste). The rest of the team, which eats at home, presents a very scarce supply of fruit and vegetables.

Breakfast and snacks are all made by themselves and are fairly balanced when compared to the guidelines for a healthy and balanced diet dictated by the American Dietetic Association (Table 2). 
Table 2. Analysis of the Recall of $24 \mathrm{~h}$

\begin{tabular}{lccccc}
\hline & Carbs (\%) & Protein (\%) & Lipid (\%) & Fruit (N./die) & Vegetables (N./die) \\
\hline Optimum Range & $50-60$ & $15-20$ & $25-30$ & $2-3$ & $>2$ \\
Average Result & 49 & 19 & 31 & 1 & 1 \\
\hline
\end{tabular}

During the nutritional assessment a survey was conducted on the amount of water taken during the day. 54\% of athletes take a daily water amount of more than 2 litres, the remaining part (46\%) of the team admits to having the incorrect drinking habit. In the totality of the team the average water intake, in terms of Litres / day, is 1.7 .

\section{Cooper and Sargent test}

Final results (Tables 5), related to the objectives of endurance and explosive strength, showed good performance for all athletes, compared to initial data (table 3), with particular importance for defenders and midfielders. After the intermediate (table 4) check for resistance only, to the search term were registered significant improvements also for athletes with the role of goalkeeper (Montesano 2016) and striker. The total percentage increase is around $+/-4 \%$.

Initial Recognition

Table 3. Initial recognition of the values of endurance and explosive strength

\begin{tabular}{lccr}
\hline Athletes & Sargent test explosive strength $(\mathbf{c m})$ & Cooper test Distance $(\mathbf{m t})$ & VO $_{2 \max }$ \\
\hline $1 \mathrm{~d}$ & 39 & 1300 & 18.35 \\
$2 \mathrm{~d}$ & 24 & 2000 & 33.75 \\
$3 \mathrm{~d}$ & 38 & 1600 & 30.45 \\
$4 \mathrm{~d}$ & 26 & 1300 & 18.35 \\
$5 \mathrm{~d}$ & 28 & 1300 & 18.35 \\
$6 \mathrm{~m}$ & 55 & 1900 & 31.55 \\
$7 \mathrm{~m}$ & 42 & 1550 & 23.85 \\
$8 \mathrm{~m}$ & 44 & 1950 & 32.65 \\
$9 \mathrm{~m}$ & 33 & 1850 & 30.45 \\
$10 \mathrm{~m}$ & 41 & 2100 & 35.95 \\
$11 \mathrm{~g}$ & 20 & 1400 & 20.55 \\
$12 \mathrm{~g}$ & 40 & 1200 & 16.15 \\
$13 \mathrm{f}$ & 44 & 1250 & 17.25 \\
$14 \mathrm{f}$ & 23 & 850 & 8.45 \\
$15 \mathrm{f}$ & 29 & 1050 & 12.85 \\
$16 \mathrm{f}$ & 23 & 1100 & 13.95 \\
$17 \mathrm{f}$ & 39 & 1200 & 16.15 \\
$18 \mathrm{f}$ & 33 & 1000 & 11.75 \\
$19 \mathrm{f}$ & 33 & 650 & 4.05 \\
$20 f$ & 34 & 900 & 9.55 \\
\hline
\end{tabular}

Intermediate Recognition

Table 4. Intermediate recognition of the values of endurance

\begin{tabular}{lccr}
\hline Athletes & Distance $(\mathbf{m t})$ & Time (minutes) & VO $_{2 \max }$ \\
\hline $1 \mathrm{~d}$ & 1400 & 11 & 24.5 \\
$2 \mathrm{~d}$ & 2000 & 12 & 35 \\
\hline
\end{tabular}




\begin{tabular}{lllr}
\hline $3 \mathrm{~d}$ & 1550 & 11 & 27.125 \\
$4 \mathrm{~d}$ & 1600 & 11 & 28 \\
$5 \mathrm{~d}$ & 1250 & 12 & 21.875 \\
$6 \mathrm{~m}$ & 1950 & 12 & 34.125 \\
$7 \mathrm{~m}$ & 1600 & 11 & 28 \\
$8 \mathrm{~m}$ & 1800 & 12 & 31.5 \\
$9 \mathrm{~m}$ & 1900 & 12 & 33.25 \\
$10 \mathrm{~m}$ & 2000 & 11 & 35 \\
$11 \mathrm{~g}$ & 1500 & 10 & 26.25 \\
$12 \mathrm{~g}$ & 1600 & 12 & 28 \\
$13 \mathrm{f}$ & 1200 & 10 & 21 \\
$14 \mathrm{f}$ & 900 & 11 & 15.75 \\
$15 \mathrm{f}$ & 1000 & 12 & 17.5 \\
$16 f$ & 1200 & 10 & 21 \\
$17 f$ & 1300 & 11 & 22.75 \\
$18 \mathrm{f}$ & 1000 & 11 & 17.5 \\
$19 f$ & 800 & 10 & 14 \\
$20 f$ & 1100 & 12 & 19.25 \\
\hline
\end{tabular}

Final Recognition

Table 5. Final recognition of the values of endurance and explosive strength

\begin{tabular}{lccc}
\hline Athletes & Sargent test explosive strength $(\mathbf{c m})$ & Cooper test Distance $(\mathbf{m t})$ & $\boldsymbol{V O}_{2 \max }$ \\
\hline $1 \mathrm{~d}$ & 45 & 1500 & 22,75 \\
$2 \mathrm{~d}$ & 34 & 2050 & 34,85 \\
$3 \mathrm{~d}$ & 41 & 1900 & 31,55 \\
$4 \mathrm{~d}$ & 26 & 1800 & 29,35 \\
$5 \mathrm{~d}$ & 34 & 1650 & 26,05 \\
$6 \mathrm{~m}$ & 55 & 2050 & 34,85 \\
$7 \mathrm{~m}$ & 47 & 1700 & 27,15 \\
$8 \mathrm{~m}$ & 56 & 2200 & 38,15 \\
$9 \mathrm{~m}$ & 39 & 1900 & 31,55 \\
$10 \mathrm{~m}$ & 47 & 1500 & 22,75 \\
$11 \mathrm{~g}$ & 32 & 1750 & 28,25 \\
$12 \mathrm{~g}$ & 44 & 1800 & 29,35 \\
$13 \mathrm{f}$ & 46 & 1450 & 21,55 \\
$14 \mathrm{f}$ & 1100 & 13,95 \\
$15 \mathrm{f}$ & 33 & 1300 & 18,35 \\
$16 \mathrm{f}$ & 36 & 1550 & 23,85 \\
$17 \mathrm{f}$ & 38 & 1550 & 23,85 \\
$18 \mathrm{f}$ & 42 & 1300 & 18,35 \\
$19 \mathrm{f}$ & 35 & 1000 & 11,75 \\
$20 \mathrm{f}$ & 42 & 1200 & 16,15 \\
\hline
\end{tabular}

Note: $G=$ goalkeeper; $D=$ defender; $M=$ midfielder; $F=$ forward

Improvement of the endurance and explosive strength parameters has increased V02max index (Figures 1, 2). 


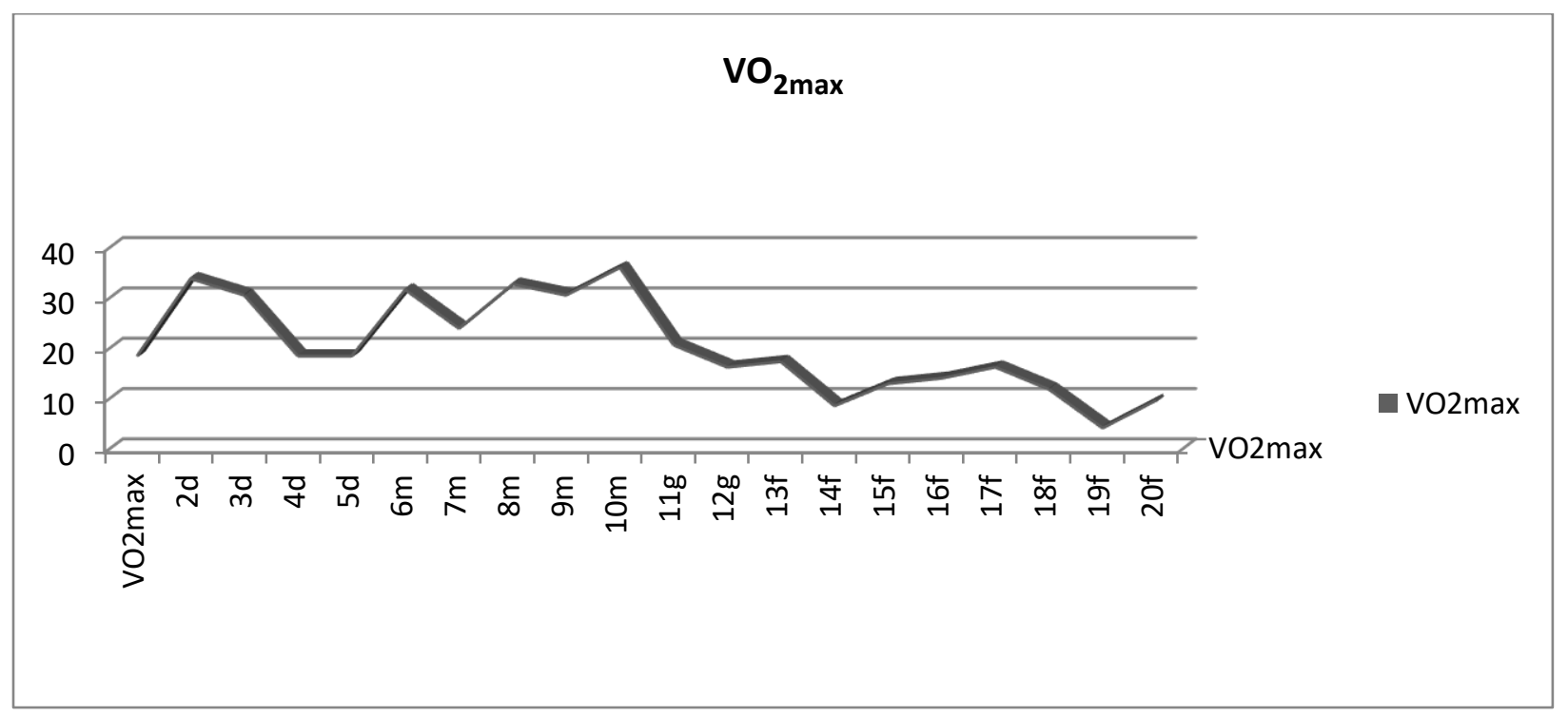

Figure 1. Initial analysis $\mathrm{VO}_{2} \max$.

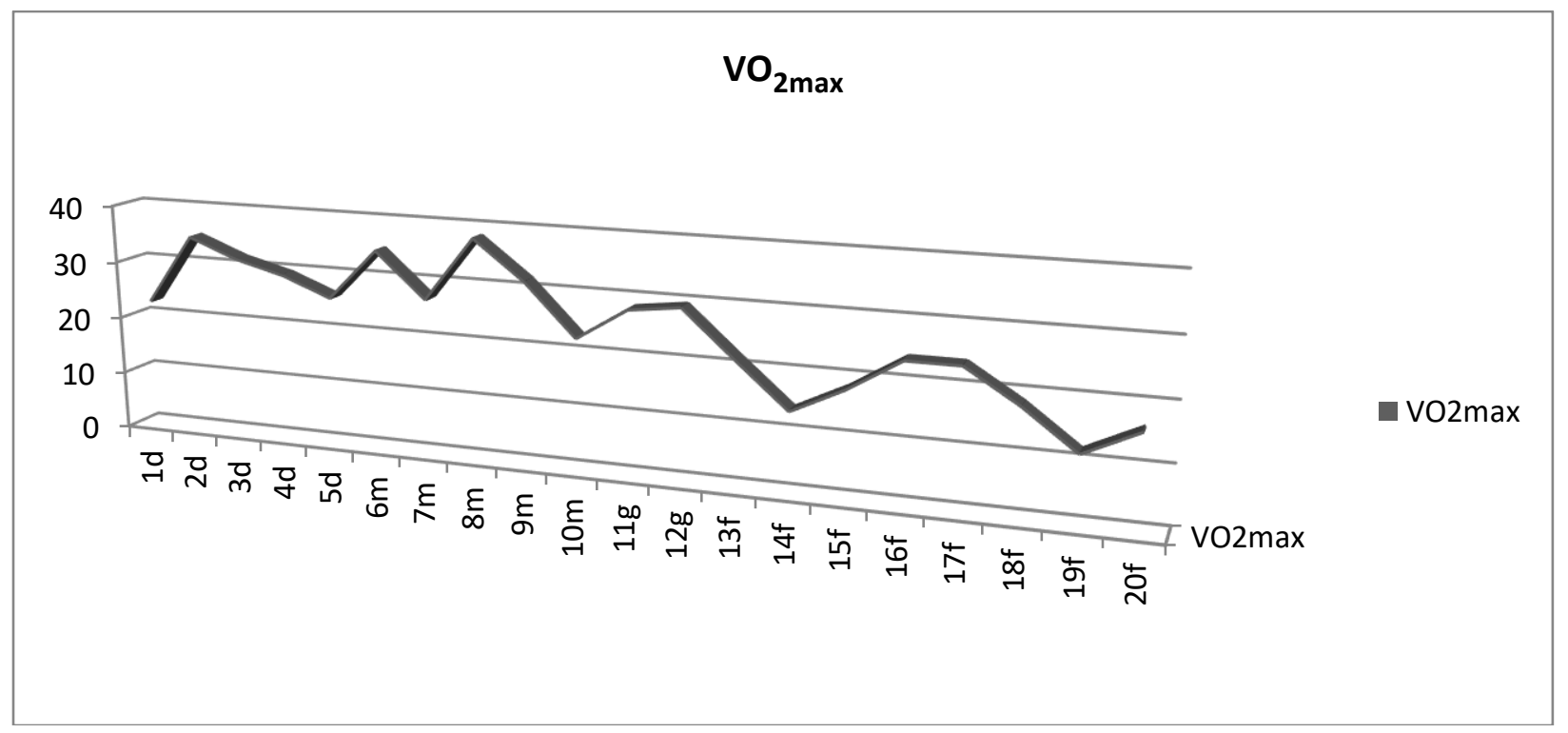

Figure 2. Final analysis $\mathrm{VO}_{2} \max$.

\section{DISCUSSION}

This study wanted to analyse some the factors, training-nutrition- biohumoral parameters, then can contribute to the realization of a state of overtraining. Many studies investigate the possible alteration of biohumoral parameters during the various phases of a Championship in relation to a state of overtraining. Of these, few make a correlation between these parameters and impedance values; no study to date has tried to find a correlation between the anthropometric parameters (especially those related to the assessment of body composition by bioimpedentric analysis) and the state of oxidative stress (urinary MDA and / or salivary DPPH). 
The results obtained during the assessment of nutritional status through the analysis of body composition shows that athletes have a good percentage of lean mass (FFM), but the same has substantial differences between athletes who occupy different roles: it is indeed greater in athletes who perform, during training but also during the game, a purely aerobic job (full backs and midfielders), which also have a very low percentage of fat mass (FM); category apart from the goalkeeper who has a high level of lean mass (FFM), due to the work of strengthening done during training, but also have a percentage of fat mass (FM) high. The same fat mass value (FM) is associated with the athletes who occupy the role of attacker in the field: this parameter is easily associated with the workload that the same, both during training and during the game, tend to perform, performing a job aerobic lower than the mates who occupy the role of midfielder or lateral.

The nutrition followed by athletes in many studies is inadequate, with deficiencies that occur especially in the Carbohydrates, with negative consequences as a result of intense training, but not only. Even nutrition, followed by athletes who have agreed to participate in the study, had been a lower carbohydrate intake than the guidelines suggested by the American Dietetic Association; the protein intake is normal (although the consumption of fish and eggs is very low); the contribution (Sirico et al., 2018) of lipids, however, slightly exceeds the normal range, especially for the excessive consumption of cheeses and sweets during and after meals. The quantity of fruit and vegetables instead does not respect the parameters indicated by the American Dietetic Association.

\section{CONCLUSION}

Sport activity is fundamental for the development of basic values for society such as group spirit and solidarity, as well as the tolerance and correctness of actions, indispensable principles for fostering daily enrichment. Through sport, we contribute to the daily improvement of the body-spirit balance, aiming not only at improving sports performance but also at improving our determination and perseverance (Mazzeo et al.,2018; D'Elia et al., 2018). In addition to having a social and educational role, sport, if properly practiced and if associated with proper nutrition, also benefits for the health of the subject and for the prevention of particular diseases that with the age advance tend to show up (D'Elia et al., 2018; Mazzeo et al., 2018).

The nutritional status plays a fundamental role in optimizing the performance of competitive athletes, but not only. In the world of sport, athletes and coaches emphasize the importance of a healthy and balanced diet both for the improvement of health and performance. Diet, training skills and functional demands directly influence sports competition, especially at high levels (Ashbaugh A., McGrew C, 2016).

In football there are many studies that show how a correct dietary intake, in terms of macro and micronutrients, positively influences sports performance, also reducing the workload (Nedelec et al., 2015).

In an overtraining condition, proper nutrition is a necessary condition but not sufficient to reduce the symptoms: there are too many parameters that contribute to the realization of this condition.

This thesis work can be considered a starting point that allows to validate a correct protocol to be used for a diagnosis of overtraining, not only in the football field. Bio-temporal parameters, psychological tests, impedance evaluation can be useful in order to carry out this diagnosis. Further studies are needed to evaluate how an overtraining condition can influence the body composition of the athlete being tested. Also based on the workload and the differences in the various sports it is possible to extend and above all complete this study in order to evaluate the fluctuations of the parameters comparing them in the literature. 
It is advisable to re-evaluate the same parameters in other phases of the championship (minimum 3: start, middle and end of the season), inserting the monitoring of other bio-temporal parameters in the study. In order to explain the result of the DPPH and the MDA it is necessary to deepen, through a compilation of a food diary (at least 7 days), knowledge on the dietary habits of individual athletes, also analysing their habits about the use of any vitamin supplements but not only. It would be useful to complete and extend the study to different categories, all with the aim of understanding how the various psychophysical components can play a key role in the diagnosis of Overtraining Syndrome.

During the course of the championship it would be advisable to provide the team with a dietary protocol aimed at satisfying nutritional needs (in terms of macro and micronutrients) and that can be considered among the parameters influencing not only the sporting performance but also the possible condition of Overtraining.

\section{CONFLICT OF INTEREST}

The authors declare that there is no conflict of interest.

\section{REFERENCES}

Altavilla, G., Mazzeo, F., D’Elia, F., \& Raiola, G. (2018). Physical commitment and specific work for each role in an elite soccer team. Journal of Physical Education and Sport, 18(2), 570-574. https://doi.org/10.7752/jpes.2018.02083

American College of Sports Medicine, American Dietetic Association, Dietitians of Canada (2000), "Joint Position Statement: nutrition and athletic performance", Med. Sci. Sports Exerc, Dec, 32(12): 213045. https://doi.org/10.1016/i.jada.2009.01.005

Ashbaugh A., McGrew C. (2016), The Role of Nutritional Supplements in Sports Concussion Treatment, Curr. Sports Med. Rep, Jan-Febr, 15(1):16-9. https://doi.org/10.1249/jsr.0000000000000219

Bangsbo J. (2015), Performance in sports-With Specific emphasis on the effect of intensified training, Scand J Med Sci Sports, Dec, 25 Suppl 4:88-99. https://doi.org/10.1111/sms.12605

Burke LM, Hawley JA (1997), Fluid balance in team sports: guidelines for optimal practices, Sports Med, 24:38-54. https://doi.org/10.2165/00007256-199724010-00004

Burns RD., Schiller MR., Merrick MA. et al. (2004), Intercollegiate student athlete use of nutritional supplements and the role of athletic trainers and dietitians in nutrition counselling , Am Diet Assoc; 104:246-49. https://doi.org/10.1016/i.jada.2003.11.013

Chulvi-Medrano, I., Picón-Martínez, M., García-Jaén, M., Cortell-Tormo, J. M., Alakhdar, Y., \& Laurentino, G. (2019). Neuromuscular adaptations after blood flow restriction training combined with nutritional supplementation: A preliminary study. Montenegrin Journal of Sports Science and Medicine, 8(1), Ahead of Print. https://doi.org/10.1249/01.mss.0000485163.70475.e8

Cipryan L., Gajda V. (2011), The influence of aerobic power on repeated anaerobic exercise in junior soccer players, J Hum Kinet, Jun, 28:63-71. https://doi.org/10.2478/v10078-011-0023-z

Fry AC., Kraemer WJ. (1997), Resistance exercise overtraining and overreaching. Neuroendocrine responses, Sports Med, Feb, 23(2):106-29. https://doi.org/10.2165/00007256-199723020-00004

Galanti G., Stefani I., Mascherini G., Buti G., Maffulli N. (2015), Eating and nutritional habits in young competitive athlete: a comparison between soccer player and cyclists, Translational Medicine, 11 (8), 44-7.

Hawley JA. Et al (1995), Nutritional practices of athletes: are they sub-optimal?, J Sports Sci, S75-81. 
Illiano, M., Nigro, E., Sapio, L., Caiafa, I., Spina, A., Scudiero, O., . . Naviglio, S. (2017). Adiponectin down-regulates CREB and inhibits proliferation of A549 lung cancer cells. Pulmonary Pharmacology and Therapeutics, 45, 114-120. https://doi.org/10.1016/i.pupt.2017.05.009

Kellmann, M. (2010). Preventing overtraining in athletes in high-intensity sports and stress/recovery monitoring. Scandinavian Journal of Medicine and Science in Sports, 20(SUPPL. 2), 95-102. https://doi.org/10.1111/j.1600-0838.2010.01192.x

Li H. et al. (2016), Acute Exercise-Induced Mitochondrial Stress Triggers an Inflammatory Response in the Myocardium via NLRP3 Inflammasome Activation with Mitophagy, Oxid Med Cell Longev, Epub. https://doi.org/10.1155/2016/1987149

Mackinnon LT. (2000), Special feature for the Olympics: effects of exercise on the immune system: overtraining effects on immunity and performance in athletes, Immunol Cell Biol, Oct, 78(5):502-9. https://doi.org/10.1111/j.1440-1711.2000.t01-7-.x

Mazzeo, F. (2016). Current concept of obesity. Sport Science, 9(2), 42-48.

Mazzeo, F. (2016b). Drug abuse in elite athletes: Doping in sports. Sport Science, 9(2), 34-41.

Mazzeo, F. (2018). Anabolic steroid use in sports and in physical activity: Overview and analysis. Sport Mont, 16(3), 113-118. https://doi.org/10.26773/smi.181020

Mazzeo, F., Santamaria, S., Montesano. P. (2019). Gender Diff erence, Nutritional supplements and Drug use in Sport to Enhancing Performance: an Italian Revision over the Last Decade, Sport Mont , 17 - 1: 69-73. https://doi.org/10.26773/smj.190212

Mazzeo, F., Santamaria, S., Monda, V., Tafuri, D., Dalia, C., Varriale, L., . . Monda, M. (2016). Dietary supplements use in competitive and non-competitive boxer: An exploratory study. Biology and Medicine, 8(4). https://doi.org/10.4172/0974-8369.1000294

Mazzeo, F., Altavilla, G., D'elia, F., \& Raiola, G. (2018). Development of doping in sports: Overview and analysis. Journal of Physical Education and Sport, 18(3), 1669-1677. https://doi.org/10.7752/ipes.2018.03244

Mazzeo, F., Monda, V., Santamaria, S., Nigro, E., Valenzano, A., Villano, I., . . Messina, G. (2018). Antidoping program: An important factor in the promotion and protection of the integrity of sport and athlete's health. Journal of Sports Medicine and Physical Fitness, 58(7-8), 1135-1145. https://doi.org/10.23736/S0022-4707.17.07722-2

Mohr M. et al. (2005), Fatigue in Soccer: a brief review, J Sports Med., Jun, 23(6):593-9.

Montesano P., Mazzeo F. (2018), Pilates Improvement the Individual Basics of Service and Smash in Volleyball, SportMont, 16(3), 25-30.

Montesano P. (2018), Monitoring and upgrading of coordinative and conditional capacities of young athletes practicing handball, Journal of Physical Education and Sport $®$ (JPES), Vol. 18 -Supplement issue 1 , Art 65, pp. $465-468$.

Montesano, P. (2014). Improvement of the coordination skills in disabled athletes special olympics. Journal of Physical Education and Sport, 14(2), 301-305. https://doi.org/10.7752/jpes.2014.02045

Montesano, P. (2016). Goalkeeper in soccer: Performance and explosive strength. Journal of Physical Education and Sport, 16(1), 230-233. https://doi.org/10.7752/ipes.2016.01036

Montesano, P., Tafuri, D., \& Mazzeo, F. (2013). Improvement of the motor performance difference in athletes of weelchair basketball. Journal of Physical Education and Sport, 13(3), 362-370. https://doi.org/10.7752/jpes.2013.03058

Nédélec, M., Halson, S., Abaidia, A. -., Ahmaidi, S., \& Dupont, G. (2015). Stress, sleep and recovery in elite soccer: A critical review of the literature. Sports Medicine, 45(10), 1387-1400. https://doi.org/10.1007/s40279-015-0358-z 
Nielsen J. et al. (2012), Skeletal Muscle glycogen content and particle size of distinct subcellular localizations in the recovery period after a high-level soccer match, Eur J Appl Physiol, Oct, 112(10):3559-67. https://doi.org/10.1007/s00421-012-2341-9

Perrotta, F., Mazzeo, F., \& Cerqua, F. S. (2017). Which treatment for obstructive airway disease: The inhaled bronchodilators. Pulmonary Pharmacology and Therapeutics, 43, 57-59. https://doi.org/10.1016/i.pupt.2017.01.003

Rescigno, T., Tecce, M. F., \& Capasso, A. (2018). Protective and restorative effects of nutrients and phytochemicals. Open Biochemistry Journal, 12, 46-64. https://doi.org/10.2174/1874091x01812010046

Selye H., (1956) The Stress of life. McGraw-Hill (Paperback), New York.

Sirico F., Miressi S., Castaldo C., Spera R., Montagnani S., Di Meglio F., Nurzynska D. (2018). Habits and beliefs related to food supplements: Results of a survey among Italian students of different education fields and levels. PLoS ONE, 13(1): e0191424. pp 1-11. https://doi.org/10.1371/journal.pone.0191424

Sirico F., Bianco A., D'Alicandro G., Castaldo C., Montagnani S., Spera R., Di Meglio F., Nurzynska D. (2018). Effects of Physical Exercise on Adiponectin, Leptin, and Inflammatory Markers in Childhood Obesity: Systematic Review and Meta-Analysis. Childhood Obesity, Volume 14, Number 4, 207-17. https://doi.org/10.1089/chi.2017.0269

Suzuki K. et al. (2002), Systemic inflammatory response to exhaustive exercise. Cytokine kinetics, Exerc Immunol. Rev., 8:6-48.

Tachè Y. (2014), Hans Seyle and the stress response: from "The First Mediator" to the identification of the Hypothalamic corticotrophin-releasing Factor, Ideggyogy Sz, Mar, 67(3-4):95-8.

\section{(C) $(1) \Theta$}

This work is licensed under a Attribution-NonCommercial-NoDerivatives 4.0 International (CC BY-NC-ND 4.0). 